\title{
Спектроскопические исследования интегрированных гетероструктур GaAs/Si
}

\author{
(С) П.В. Середин ${ }^{1,2}$, Д.Л. Голощапов ${ }^{1}$, И.Н. Арсентьев ${ }^{3}$, Д.Н. Николаев ${ }^{3}$, Н.А. Пихтин ${ }^{3}$, С.О. Слипченко $^{3}$ \\ ${ }^{1}$ Воронежский государственный университет, \\ 394018 Воронеж, Россия \\ ${ }^{2}$ Уральский федеральный университет им. первого Президента России Б.Н. Ельцина, \\ 620002 Екатеринбург, Россия \\ ${ }^{3}$ Физико-технический институт им. А.Ф. Иоффе Российской академии наук, \\ 194021 Санкт-Петербург, Россия \\ E-mail: paul@phys.vsu.ru, arsentyev@mail.ioffe.ru
}

Поступила в Редакцию 3 сентября 2020 г.

В окончательной редакции 10 сентября 2020 г.

Принята к публикации 10 сентября 2020 г.

Целью работы являлось исследование влияния нового типа податливых подложек на основе сверхструктурного слоя (SL) AlGaAs и слоя протопористого кремния (proto-Si), сформированного на $c$ - $\mathrm{Si}$, на оптические свойства эпитаксиального слоя GaAs, выращенного методом MOC-гидридной эпитаксии. Впервые показано, что низкотемпературный рост высококачественных эпитаксиальных пленок GaAs может быть реализован за счет использования податливых подложек SL/proto-Si. Введение SL в состав податливой подложки в дополнение к proto-Si позволяет нивелировать ряд негативных эффектов низкотемпературного роста, снизить уровень напряжений в эпитаксиальном слое, защитить от автолегирования атомами кремния, сократить число технологических операций по росту переходных буферных слоев, улучшить структурные и морфологические характеристики эпитаксиального слоя, а также достичь хороших оптических характеристик слоя. Проведены исследования полученных гетероструктур $\mathrm{GaAs} / \mathrm{Si}$ методами рамановской спектроскопии, фотолюминесценции, спектроскопии оптического пропускания-отражения. Полученные данные послужат важным материалом для понимания основ физики и технологии интегрированных гетероструктур $\mathrm{A}^{\mathrm{III}} \mathrm{B}^{\mathrm{V}} / \mathrm{Si}$, способствуя их применению в устройствах оптоэлектроники.

Ключевые слова: гетероструктура $\mathrm{GaAs} / \mathrm{Si}$, податливая подложка, proto-Si, сверхструктурный слой, рамановская спектроскопия, фотолюминесценция, оптические спектры

DOI: 10.21883/FTP.2021.01.50383.9519

\section{1. Введение}

Совмещение соединений $\mathrm{A}^{\mathrm{III}} \mathrm{B}^{\mathrm{V}}$, таких как полупроводники группы GaAs, с кремниевыми подложками предоставляет уникальный шанс объединить преимущества передовых полупроводниковых материалов с возможностями, развитыми кремниевой технологией. В итоге это позволит создать высокоскоростные и мощные устройства оптоэлектроники, солнечные элементы, светодиоды, лазеры и т.д. [1-3].

В ряде предыдущих работ [4-7] мы показали, что для создания гибридных гетероструктур $\mathrm{GaAs} / \mathrm{Si}$ с высокими функциональными характеристиками весьма перспективно применение податливой подложки, которая представляет собой переходный нанопористый слой кремния, созданный непосредственно на монокристалле $c$-Si методом электрохимического травления. Использование податливой подложки типа proto-Si/Si позволяет добиться уникальных оптических и электрофизических характеристик гибридных гетероэпитаксиальных структур $\mathrm{A}^{\mathrm{III}} \mathrm{B}^{\mathrm{V}} /$ proto-Si/Si, сочетающих лучшие транспортные и оптические характеристики разнородных материалов в одном устройстве, и в итоге снизить стоимость готовых устройств за счет сокращения числа дополнительных технологических процессов.
Еще одним технологическим приемом для создания нового типа податливых подложек может стать введение в ее состав сверхструктурных слоев (SL) $\mathrm{A}^{\mathrm{III}} \mathrm{B}^{\mathrm{V}}$. В уже выполненных нами работах [8-11] для систем полупроводниковых соединений $\mathrm{A}^{\mathrm{III}} \mathrm{B}^{\mathrm{V}}$ (AlGaAs, GaInP, InGaAs и др.) удалось показать перспективность данного подхода.

Однако информации об оптических свойствах эпитаксиальных слоев GaAs, выращенных на податливой подложке SL/proto-Si, в литературе нет. Поэтому целью данной работы стали спектроскопические исследования гетероструктур $\mathrm{A}^{\mathrm{III}} \mathrm{B}^{\mathrm{V}}$ /proto-Si/Si, а также сопоставление полученных результатов с достижениями при использовании технологии выращивания на стандартных подложках.

\section{2. Материалы и методы}

Исследуемые структуры выращивались методом MOC-гидридной эпитаксии (газофазной эпитаксии из металлоорганических соединений, MOCVD) на установке EMCORE GS3100 с реактором вертикального типа и резистивным нагревом подложкодержателя. Давление в реакторе - 77 Торр, скорость вращения подложкодержате- 
ля - 1000 об/мин. В качестве источников служили триметилгаллий $\mathrm{Ga}\left(\mathrm{CH}_{3}\right)_{3}$, триметилалюминий $\mathrm{Al}\left(\mathrm{CH}_{3}\right)_{3}$ и арсин $\mathrm{AsH}_{3}$. В качестве газа-носителя использовался водород $\left(\mathrm{H}_{2}\right)$. Для роста структур были использованы подложки $\mathrm{Si}(100)$ с разориентацией $3^{\circ}$ к (110).

Выращивание структур осуществлялось по следующей технологии.

На первом этапе аналогично тому, как это было сделано в наших предыдущих работах [5,6], на поверхности $\mathrm{Si}$ был сформирован протопористый слой путем травления исходной подложки в течение 1 мин в растворе следующего состава: 1 часть $\mathrm{HF}+1$ часть уксусной кислоты +40 частей азотной кислоты.

Далее обработанная подложка $\mathrm{Si}$ отжигалась в $\mathrm{AsH}_{3}$ в течение 20 мин при температуре $750^{\circ} \mathrm{C}$. После этого температура понижалась в течение 7 мин до $450^{\circ} \mathrm{C}$ при потоке $\mathrm{AsH}_{3}$.

На следующем этапе были выращены эпитаксиальный слой AlAs толщиной 10 нм и GaAs толщиной 30 нм, после чего температура повышалась в течение 7 мин до $550^{\circ} \mathrm{C}$ при потоке $\mathrm{AsH}_{3}$. При этой температуре для структуры А выращивался слой GaAs толщиной 360 нм, а для структуры В был выращен сверхструктурный слой (SL) AlGaAs толщиной $\sim 100$ нм и сверху слой GaAs толщиной 700 нм.

Для сравнения полученных результатов мы использовали гомоэпитаксиальную структуру GaAs/GaAs, выращенную по стандартной технологии и изученную нами ранее [5]. Эта гетероструктура выращивалась при следующих условиях: температура подложкодержателя во время эпитаксиального роста $-700^{\circ} \mathrm{C}$, давление в реакторе - 77 Торр, скорость вращения подложкодержателя - 1000 об/мин. В качестве исходных реагентов использовались триметилгаллий $\mathrm{Ga}\left(\mathrm{CH}_{3}\right)_{3}$, триметилалюминий $\mathrm{Al}\left(\mathrm{CH}_{3}\right)_{3}$ и арсин $\mathrm{AsH}_{3}$. Скорость роста $\mathrm{GaAs}$ составила $\sim 770 \AA /$ мин.

Рамановские спектры были получены на конфокальном рамановском микроскопе RamMix 532 со спектральным разрешением: $2 \mathrm{~cm}^{-1}$ в диапазоне: $200-2000 \mathrm{~cm}^{-1}$. Возбуждение осуществлялось лазером с длиной волны $\lambda_{\mathrm{ex}}=532$ нм, мощность на образце $\sim(10-50)$ мВт. Сигнал собирали с использованием объектива $50 \times$.

Спектры фотолюминесценции гетероструктур получены при комнатной температуре от поверхности образцов по стандартной методике на основе монохроматора TRIAX550, охлаждаемого жидким азотом CCD-детектоpa, при возбуждении аргоновым лазером с длиной волны 514.5 нм. Облучаемая площадь поверхности образца составляла $1 \mathrm{mм}^{2}$. Для фокусировки на поверхности использовался объектив $10 \times$.

\section{3. Экспериментальные данные и их обсуждение}

\section{1. Рамановская спектроскопия}

Для изучения структурных особенностей эпитаксиального роста гибридных структур, полученных на по-

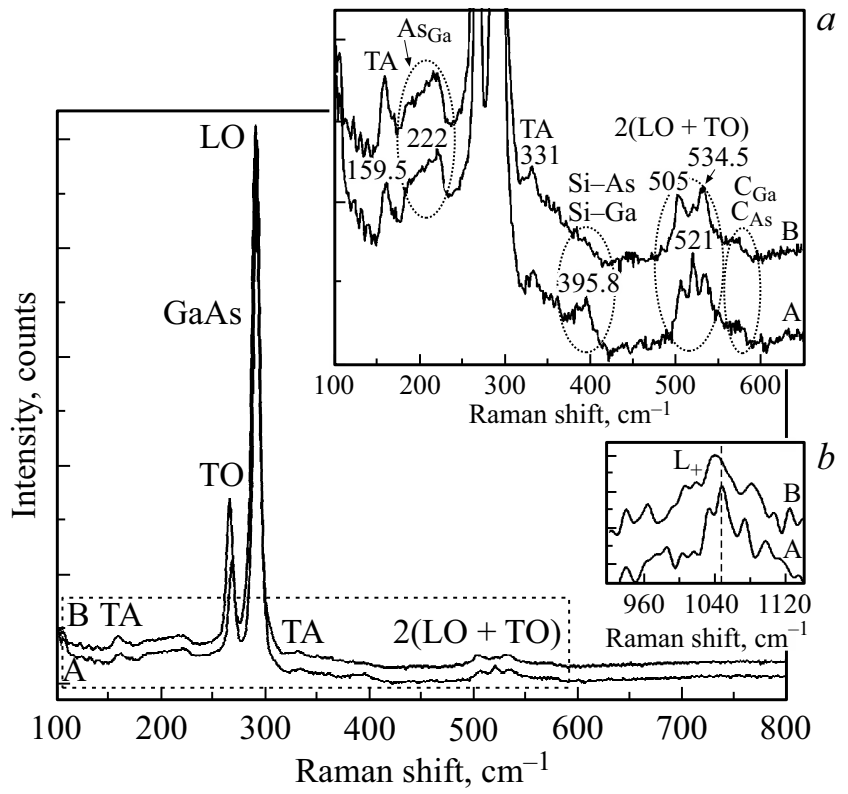

Рис. 1. Спектры рамановского рассеяния для пленок $\mathrm{GaAs}$, выращенных на подложках proto- $\mathrm{Si}(100)$ и $\mathrm{SL} /$ proto-Si(100). На вставках - колебания низкой интенсивности в рамановских спектрах интегрированных гетероструктур в области $100-650(a)$ и $940-1030 \mathrm{~cm}^{-1}(b)$.

датливых подложках двух типов, нами была использована рамановская спектроскопия. Использование рамановского рассеяния дает дополнительную, новую и иногда подробную информацию относительно свойств и кристаллического качества слоев в эпитаксиальных гетероструктурах [12-14].

Хорошо известно, что GaAs имеет структуру типа цинковой обманки, в которой на элементарную ячейку приходятся два разных атома. В соответствии с тензором рамановского рассеяния в спектре GaAs должны проявиться акустические (3 типа) и оптические (3 типа) фононы. При этом правила отбора допускают появление только продольных оптических (LO) фононов с поверхности (100), оптических поперечных (ТО) фононов с поверхности (110), а также LO- и TO-фононов с поверхности (111) [15]. Однако с учетом выбранной нами геометрии съемки $z(x y) z$ для эпитаксиального слоя с ориентацией (100) и структурой сфалерита разрешенными в спектре являются лишь LO-фононы, распространяющиеся вдоль нормали к (001).

На рис. 1 приведены экспериментальные спектры рамановского рассеяния для гетероструктур А и В, выращенных на податливых подложках proto-Si и $\mathrm{SL} /$ proto-Si.

Можно заметить, что в спектрах образцов основным высокоинтенсивным рефлексом является продольное колебание $\mathrm{LO}_{\mathrm{Ga}-\mathrm{As}}$. Кроме того, в спектрах проявляются запрещенные поперечные фононы $\mathrm{TO}_{\mathrm{Ga}-\mathrm{As}}$, что указывает на отклонение ориентации эпитаксиального слоя GaAs от направления (100), возникшее вследствие роста на подложке $\mathrm{Si}(100)$ с разориентацией от направле- 


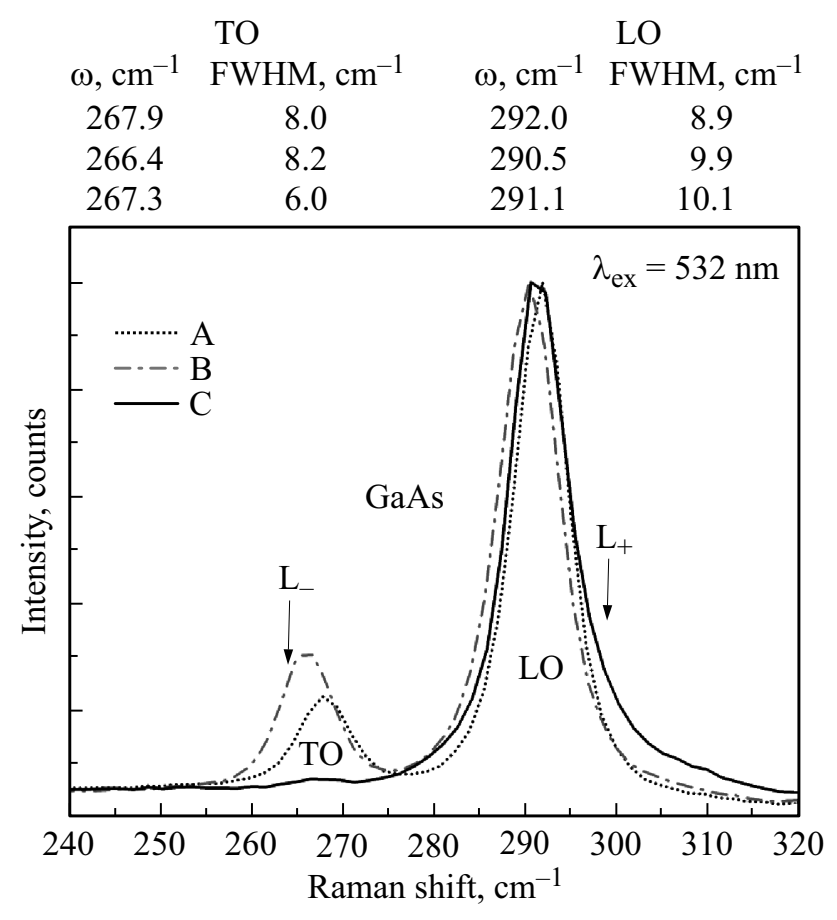

Рис. 2. Область LO- и TO-фононов в рамановском спектре эпитаксиального слоя GaAs гетероструктур A, В и гомоэпитаксиальной структуры C.

ния (100). Более детально область LO- и ТО-фононов в эпитаксиальном слое GaAs представлена на рис. 2. Кроме того, для сравнения на рис. 2 представлен спектр гомоэпитаксиального образца $\mathrm{C}$, выращенного по стандартной технологии. Отсутствие моды ТО в спектре образца С указывает на идеальную ориентацию эпитаксиального слоя GaAs. Кроме того видно, что положение продольной и поперечной мод в пленках $\mathrm{GaAs}$, выращенных на податливых подложках, сдвинуто относительно такового для гомоэпитаксиальной структуры, для которой частоты фононных мод прекрасно совпадают с известными литературными значениями для монокристалла GaAs [16]. Положения $(\omega)$ и полуширины (FWHM) полос LO- и ТO-фононов отражены на рис. 2. Следует отметить, что наблюдаемая на рис. 2 асимметрия в форме LO- и ТО-колебаний гомоэпитаксиального образца С связана с появлением плазмон-фононного взаимодействия $\mathrm{L}_{+}$и $\mathrm{L}_{-}$. Относительно полуширины полосы LO-фононов для образцов А и В можно сказать, что она не превышает $10 \mathrm{~cm}^{-1}$, и это является показателем высокого кристаллического качества выращенных пленок.

Помимо основных фононных мод в рамановских спектрах обоих образцов присутствует ряд низкоинтенсивных колебаний, которые хорошо видны на рис. $1, a, b$. В спектрах наблюдаются акустические фононы ТА вблизи 160 и $330 \mathrm{~cm}^{-1}$ [17]. Появление низкоинтенсивной структуры между 500 и $530 \mathrm{~cm}^{-1}$ в образцах обусловлено фононным рассеянием 2-го порядка [18]. Наблюдае- мые незначительные различия в спектрах в этой области обусловлены смещениями в геометрии рассеяния.

Колебание, локализованное вблизи $390 \mathrm{~cm}^{-1}$, может быть ассоциировано с внедрением атомов $\mathrm{Si}$ в решетку $\mathrm{GaAs}$, вследствие чего в рамановском спектре могут появляться локальные моды $\mathrm{Si}-\mathrm{Ga}$ либо $\mathrm{Si}-\mathrm{As}$ при $390 \mathrm{~cm}^{-1}$ [19]. Хорошо видно, что колебание в этой области присутствует лишь в спектре гетероструктуры А. Введение в состав податливой подложки SL защищает эпитаксиальный слой от автолегирования атомами кремния, диффундирующими из подложки.

Выращивание методом MOCVD при пониженных температурах способствует автолегированию эпитаксиальных слоев атомами углерода в процессе роста [14], в связи с чем в спектрах могут наблюдаться линии углерода. В соответствии с данными работы [20] линии углерода в спектрах рамановского рассеяния должны быть локализованы вблизи $580 \mathrm{~cm}^{-1}$. Как видно из экспериментальных данных (см. рис. 1, $a$ ), в спектрах гетероструктур А и В в этой области наблюдается слабый отклик рассеяния, что указывает на небольшую концентрацию углерода, встроившегося в кристаллическую решетку GaAs в процессе роста.

Широкая линия, наблюдаемая в рамановских спектрах в области $200-230 \mathrm{~cm}^{-1}$, также является следствием низкотемпературного роста пленок GaAs и связана с избыточной концентрацией As, а также сопутствующих точечных дефектов, таких как антиструктурные дефекты $\mathrm{As}_{\mathrm{Ga}}$ и вакансии $\mathrm{Ga}[15]$.

Еще одной особенностью в спектрах гетероструктур, выращенных на податливых подложках, является появление моды в области $1040 \mathrm{~cm}^{-1}$ (см. рис. $1, b$ ). В соответствии с данными работ $[18,21]$ это колебание является плазмоноподобной модой $\mathrm{L}_{+}$слоя GaAs $n$-типа проводимости, интенсивность которой зависит от концентрации свободных носителей заряда. Следует отметить, что в работе [18] интенсивность колебания в этой области спектра по отношению к интенсивности LO-моды GaAs значительно выше наблюдаемой в наших спектрах. При этом концентрация носителей заряда в [18] была на уровне $\sim 10^{19} \mathrm{~cm}^{-3}$.

Как было неоднократно показано, рамановская спектроскопия является чувствительным инструментом для измерения напряжений в эпитаксиальных слоях. Происхождение напряжений может быть тепловым, т.е. связанным с различными температурными коэффициентами расширения материалов, входящих в гетеропару, или из-за температурных градиентов во время роста образца. Однако основной предпосылкой напряжений является различие в параметрах решетки материалов.

Анализ напряжений в слое может быть выполнен исходя из сдвига TO-/LO-фононной моды. При этом сдвиг будет положительным при сжимающем напряжении в слое и отрицательным при возникновении растягивающих напряжений.

Существование этих напряжений представляет собой серьезную проблему для работы устройства, так 
Таблица 1. Результаты рамановской спектроскопии

\begin{tabular}{c|c|c}
\hline Структура & $\Delta \omega_{0}, \mathrm{~cm}^{-1}$ & $\sigma, \mathrm{M \Pi а}$ \\
\hline $\mathrm{A}$ & 0.9 & 212 \\
$\mathrm{~B}$ & -0.6 & 141
\end{tabular}

как они могут вызвать образование дефектов, таких как дислокации, приводящих к образованию трещин и уменьшающих срок службы устройства.

Поскольку для полупроводниковых эпитаксиальных слоев с кубической решеткой и ориентацией поверхности (001) в рамановском спектре разрешены только LO-фононы, величина остаточных напряжений кристаллической решетки может быть оценена по рамановскому сдвигу фононной полосы LO.

В соответствии с данными из работы [21] рамановский сдвиг $\Delta \omega_{0}$, обусловленный напряжениями, может быть определен из следующего соотношения:

$$
\Delta \omega_{0}=\frac{1}{\omega_{0}}\left[S_{11} p+\left(S_{12}+S_{11}\right) q\right] \sigma,
$$

где $S_{i j}$ - коэффициенты упругой податливости, $p$ и $q-$ константы, показывающие, как коэффициенты упругой податливости меняются под действием напряжения, $\sigma-$ механическое напряжение.

Соотношения между рамановским сдвигом $\Delta \omega_{0}$ и напряжением $\sigma$ в кристалле GaAs в зависимости от типа гетероперехода были получены экспериментально [22]. В случае биаксиального напряжения $\sigma$ (в ГПа) в плоскости (100) для гетероперехода $\mathrm{GaAs} / \mathrm{Si}$ справедливо следующее соотношение для рамановского сдвига $\left(\right.$ в $\left.\mathrm{cm}^{-1}\right)$ :

$$
\Delta \omega_{0}=4.24 \sigma
$$

Сдвиги LO- и TO-фононов в эпитаксиальных слоях GaAs (см. рис. 2), выращенных на податливых подложках, относительно положения этих колебаний в гомоэпитаксиальной структуре приведены в табл. 1. Можно заметить, что в соответствии с направлением сдвига $\Delta \omega_{0}$ эпитаксиальный слой GaAs в гетероструктуре A испытывает сжимающие напряжения, в то время как отрицательный сдвиг $\Delta \omega_{0}$ для гетероструктуры В указывает на возникновение растягивающих напряжений. Эти результаты согласуются с данными рентгеновской дифракции, на основе которой был определен параметр кристаллической решетки эпитаксиальной пленки GaAs с учетом внутренних напряжений $\left(a^{v}\right)$.

С использованием соотношения (2) мы рассчитали величины $\sigma$ для гетероструктур А и В, которые представлены в табл. 1.

Хорошо видно, что напряжение в эпитаксиальном слое GaAs гетероструктуры, выращенной на податливой подложке SL/proto-Si, практически на 50\% меньше, чем для гетероструктуры, сформированной на подложке proto-Si.
Отметим, что определенный по рамановским данным уровень напряжений отражает их состояние в верхних слоях эпитаксиального слоя GaAs, так как эффективная глубина рассеяния составляет $\sim 100 \mathrm{нм.}$

\section{2. Оптическая спектроскопия}

Оптические свойства гетероструктур в ультрафиолетовом и видимом диапазонах были изучены на основе подхода, который мы многократно использовали в наших предыдущих работах, с применением методики съемки на отражение, апробированной нами в серии предыдущих работ [23-26]. Использование этого подхода дает возможность изучить оптические фундаментальные свойства эпитаксиальных пленок, выращенных на различных подложках.

Для этого при падении электромагнитного излучения, близком к падению по нормали, мы получили спектры пропускания-отражения гетероструктур $\mathrm{GaAs} / \mathrm{Si}$ в области длин волн 190-900 нм. Экспериментальные спектры пропускания-отражения представлены на рис. 3. Как хорошо видно из рис. 3, спектры содержат ряд характерных особенностей. В соответствии с фундаментальными представлениями [27] максимумы в спектрах пропускания-отражения образцов соответствуют переходам в точках $\Gamma$, L и $\Lambda$ для GaAs, причем переходы в точках $\mathrm{L}$ и $\Lambda$ являются дублетами в результате спинорбитального расщепления валентной зоны.

Для выявления особенностей в механизмах оптического поглощения в эпитаксиальном слое GaAs на основе формулы Ламберта-Бугера

$$
T=\exp [-D]
$$

и соотношений Крамерса-Кронига [28] спектры пропускания-отражения были трансформированы в спектры поглощения. Здесь $T-$ коэффициент пропускания, $D-$

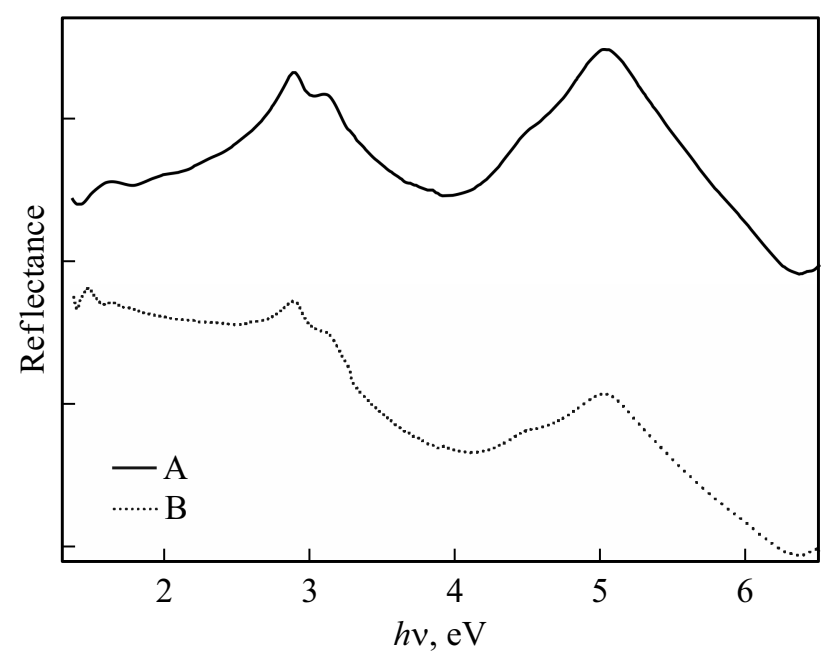

Рис. 3. Экспериментальные спектры пропускания-отражения при угле падения излучения $8^{\circ}$ гетероструктур, выращенных на подложках proto-Si(100) и $\mathrm{SL} /$ proto-Si(100). 
Таблица 2. Результаты анализа оптических спектров образцов гетероструктур

\begin{tabular}{c|c|c|c|c|c}
\hline \multirow{2}{*}{ Образец } & \multicolumn{5}{|c}{$\begin{array}{r}\text { Прямые переходы и особенности в спектрах, их принадлежность } \\
\text { в соответствии с данными из работы [27] }\end{array}$} \\
\cline { 2 - 6 } & \multicolumn{2}{|c|}{$\Lambda 3-\Lambda 1$} & L3-L1 & Г15-Г15 & X5-X1 \\
\hline A & 2.9 & 3.13 & 2.48 & 4.78 & 5.03 \\
B & 2.88 & 3.10 & 2.58 & 4.50 & 5.03 \\
GaAs [27] & 2.90 & 3.14 & 2.6 & 4.2 & 5.12 \\
\end{tabular}
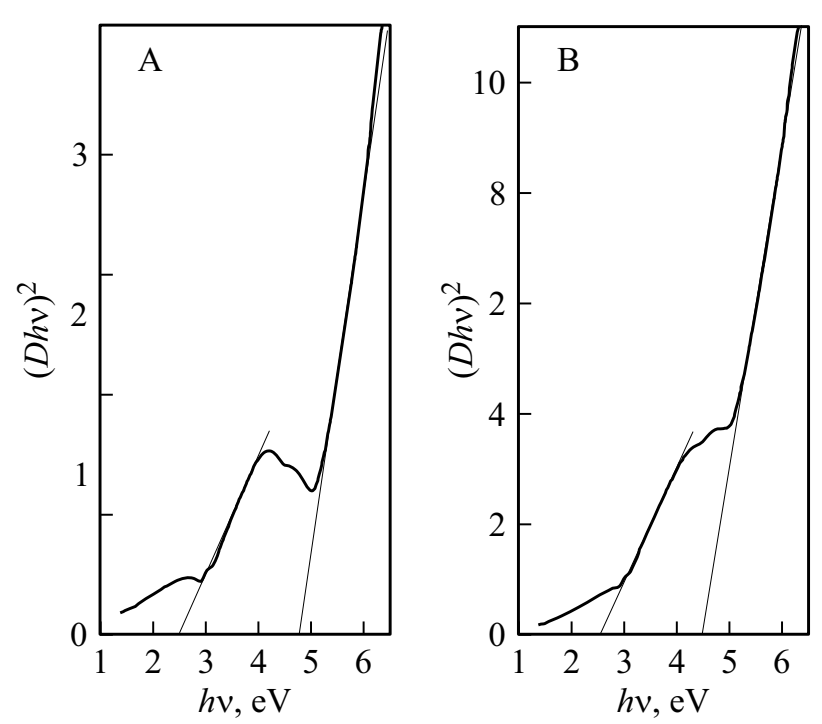

Рис. 4. Зависимости $(D h v)^{2}$ от энергии фотонов $h v$ для образцов интегрированных гетероструктур $\mathrm{GaAs} /$ proto-Si(100) (образец А) и $\mathrm{GaAs} / \mathrm{SL} /$ proto-Si(100) (образец B).

оптическая плотность. Далее была построена зависимость $(D h v)^{2}$ от энергии фотонов $h v$ (рис. 4).

Графический анализ этой зависимости дает возможность выявить в ней участки с линейной зависимостью (рис. 4). Линейная экстраполяция данных участков к нулевому значению позволяет определить энергию прямых переходов, характерных для образцов.

В табл. 2 представлены энергии прямых переходов и особенностей, присутствующих в спектрах образцов, определенные по описанной методике, а также известные литературные данные для монокристаллического GaAs [27].

Относительно особенностей в спектрах интегрированных гетероструктур $\mathrm{GaAs} / \mathrm{Si}$ следует отметить, что их энергетическое положение практически совпадает с данными для монокристаллического GaAs. Однако необходимо отметить, что в спектре GaAs, выращенного на податливых подложках, заметен сдвиг в сторону бо́льших энергий для прямых переходов в точке Г, а в точке $\mathrm{L}$ - в низкоэнергетическую область. При этом c ростом остаточных напряжений сдвиг увеличивается. Сравнивая полученные результаты и данные нашей предыдущей работы, в которой мы исследовали гомо- эпитаксиальную структуру GaAs/GaAs (образец C) и определили влияние разориентации подложки $\mathrm{Si}$, а также ее предварительного травления на оптические свойства эпитаксиального слоя GaAs, следует отметить прямую корреляцию полученных данных. При этом введение SL в состав податливой подложки положительно сказывается на оптических характеристиках эпитаксиальной пленки, что проявляется в меньших энергетических сдвигах для разрешенных прямых переходов.

\section{3. Фотолюминесценция}

Кристаллическое качество эпитаксиального слоя $\mathrm{GaAs}$, а также изменение стехиометрии при росте на податливой подложке с суперслоем неизменно должны отразиться на характере фотолюминесценции (ФЛ), т. е. на энергетических характеристиках образцов.

Спектры ФЛ двух образцов гетероструктур, а также образца гомоэпитаксиальной структуры С представлены на рис. 5. Как следует из экспериментальных данных, эпитаксиальные слои GaAs, выращенные на податливых положках proto-Si и $\mathrm{SL} /$ proto-Si, а также на подложке $\mathrm{GaAs}$, имеют одномодовую структуру. Линия расположена в диапазоне энергий $\sim(1.47-1.5)$ эВ и представляет собой излучательные переходы зона-зона, совпадающие по энергии с шириной запрещенной зоны

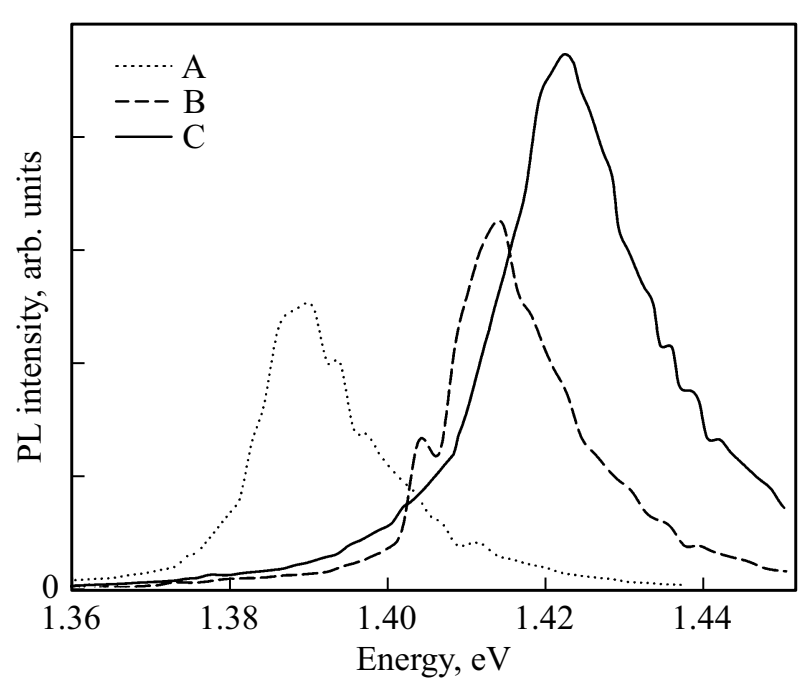

Рис. 5. Спектры фотолюминесценции гетероструктур А, В и гомоэпитаксиальной структуры C при комнатной температуре. 
GaAs. Интенсивность ФЛ и положение полосы в спектре зависят от типа образца. Максимальную интенсивность ФЛ имеет гомоэпитаксиальный образец С. Сдвиг максимума полосы фотолюминесценции гетероструктур А и В относительно положения максимума для гомоэпитаксиальной структуры С обусловлен напряжениями в кристаллической решетке и коррелирует с величиной упругих напряжений, наблюдаемых в эпитаксиальном слое GaAs (табл. 2).

\section{4. Заключение}

Наши экспериментальные результаты показывают, что введение SL в состав податливой подложки позволяет нивелировать ряд негативных эффектов низкотемпературного роста, перераспределить возникающие напряжения в кристаллической решетке, а также сократить число технологических операций по росту переходных буферных слоев.

В соответствии с данными рамановской спектроскопии напряжения в эпитаксиальном слое GaAs, вызванные рассогласованием кристаллических решеток, в случае гетероструктуры, выращенной на податливой подложке $\mathrm{SL} /$ proto-Si, практически на 50\% меньше, чем для гетероструктуры, сформированной на подложке proto-Si. Сдвиг максимума полосы фотолюминесценции гетероструктур обусловлен напряжениями в кристаллической решетке и коррелирует с величиной упругих напряжений, наблюдаемой в эпитаксиальном слое GaAs.

Введение SL в состав податливой подложки положительно сказывается на оптических свойствах эпитаксиальной пленки, что проявляется в меньших энергетических сдвигах для разрешенных прямых переходов.

Полученные данные послужат важным материалом для понимания основ физики и технологии интегрированных гетероструктур $\mathrm{A}^{\mathrm{III}} \mathrm{B}^{\mathrm{V}} / \mathrm{Si}$, способствуя развитию их потенциала для применения в устройствах оптоэлектроники.

\section{Финансирование}

Работа выполнена при финансовой поддержке гранта Российского научного фонда 19-72-10007.

Свою часть работы П.В. Середин выполнил при поддержке гранта Министерства науки и высшего образования Российской Федерации No. FZGU-2020-0036 в рамках государственного задания вузам.

Технологические исследования эпитаксиальных процессов методом MOCVD были выполнены по государственной плановой программе ФТИ им. А.Ф. Иоффе.

\section{Благодарности}

We acknowledge the Karlsruhe Nano Micro Facility (KNMF, www.kit.edu/knmf) of the Forschungszentrum Karlsruhe for provision of access to instruments at their laboratories.

\section{Конфликт интересов}

Авторы заявляют об отсутствии конфликта интересов.

\section{Список литературы}

[1] A. Ballabio, S. Bietti, A. Scaccabarozzi, L. Esposito, S. Vichi, A. Fedorov, A. Vinattieri, C. Mannucci, F. Biccari, A. Nemcsis, L. Toth, L. Miglio, M. Gurioli, G. Isella, S. Sanguinetti. Sci. Rep., 9, (2019). doi:10.1038/s41598-019-53949-x

[2] M. Feifel, D. Lackner, J. Ohlmann, J. Benick, M. Hermle, F. Dimroth. Sol. RRL, 3, 1900313 (2019). doi:10.1002/solr.201900313

[3] A.A. Geldash, V.N. Djuplin, V.S. Klimin, M.S. Solodovnik, O.A. Ageev. J. Phys. Conf. Ser., 1410, 012030 (2019). doi:10.1088/1742-6596/1410/1/012030

[4] P.V. Seredin, D.L. Goloshchapov, A.S. Lenshin, A.M. Mizerov, D.S. Zolotukhin. Phys. E: Low-Dim. Syst. Nanostructur., 104, 101 (2018). doi:10.1016/j.physe.2018.07.024

[5] P.V. Seredin, A.S. Lenshin, D.S. Zolotukhin, I.N. Arsentyev, A.V. Zhabotinskiy, D.N. Nikolaev. Phys. E: Low-Dim. Syst. Nanostructur., 97, 218 (2018). doi:10.1016/j.physe.2017.11.018

[6] P.V. Seredin, A.S. Lenshin, D.S. Zolotukhin, I.N. Arsentyev, D.N. Nikolaev, A.V. Zhabotinskiy. Phys. B: Condens. Matter, 530, 30 (2018). doi:10.1016/j.physb.2017.11.028

[7] P.V. Seredin, A.S. Lenshin, A.M. Mizerov, H. Leiste, M. Rinke. Appl. Surf. Sci., 476, 1049 (2019). doi:10.1016/j.apsusc.2019.01.239

[8] P.V. Seredin, A.V. Glotov, E.P. Domashevskaya, I.N. Arsentyev, D.A. Vinokurov, I.S. Tarasov. Appl. Surf. Sci., 267, 181 (2013). doi:10.1016/j.apsusc.2012.09.053

[9] E.P. Domashevskaya, P.V. Seredin, A.N. Lukin, L.A. Bityutskaya, M.V. Grechkina, I.N. Arsentyev, D.A. Vinokurov, I.S. Tarasov. Surf. Interface Anal., 38, 828 (2006). doi:10.1002/sia.2306

[10] P.V. Seredin, D.L. Goloshchapov, Yu.Yu. Khudyakov, A.S. Lenshin, A.N. Lukin, I.N. Arsentyev, T. Prutskij. Phys. B: Condens. Matter, 509, 1 (2017). doi:10.1016/j.physb.2016.12.030

[11] T. Prutskij, P. Seredin, G. Attolini. J. Luminesc., 195, 334 (2018). doi:10.1016/j.jlumin.2017.11.016

[12] P.V. Seredin, A.S. Lenshin, A.V. Glotov, I.N. Arsentyev, D.A. Vinokurov, I.S. Tarasov, T. Prutskij, H. Leiste, M. Rinke. Semiconductors, 48, 1094 (2014). doi:10.1134/S1063782614080211

[13] P. Seredin, A. Glotov, E. Domashevskaya, I. Arsentyev, D. Vinokurov, A. Stankevich, I. Tarasov. In: Adv. Mater. Technol. MicroNano-Devices Sensors Actuators, ed. by E. Gusev, E. Garfunkel, and A. Dideikin (Springer Netherlands, Dordrecht, 2010) p. 225.

[14] P.V. Seredin, A.V. Glotov, E.P. Domashevskaya, I.N. Arsentyev, D.A. Vinokurov, I.S. Tarasov. Phys. B: Condens. Matter, 405, 2694 (2010). doi:10.1016/j.physb.2010.03.049

[15] D.-S. Jiang, X.-P. Li, B.-Q. Sun, H.-X. Han. J. Phys. D: Appl. Phys., 32, 629 (1999). doi:10.1088/0022-3727/32/6/005

[16] Properties of Semiconductor Alloys: Group-IV, III-V and II-VI Semiconductors,1st edn, ed. by Sadao Adachi (Wiley, Chichester, UK, 2009). 
[17] N.M. Belyi, O.V. Vakulenko, V.A. Gubanov, V.A. Skryshevskii. J. Appl. Spectrosc., 41, 938 (1984). doi:10.1007/BF00659848

[18] W.Q. Li, P.K. Bhattacharya, S.H. Kwok, R. Merlin. J. Appl. Phys., 72, 3129 (1992). doi:10.1063/1.351474

[19] A.G. Rodríguez, H. Navarro-Contreras, M.A. Vidal. J. Appl. Phys., 90, 4977 (2001). doi:10.1063/1.1410886

[20] B. Pajot, B. Clerjaud, B. Pajot. Electronic Absorption of Deep Centres and Vibrational Spectra (Springer, Heidelberg, 2013).

[21] S. Perkowitz. Optical Characterization of Semiconductors: Infrared, Raman, and Photoluminescence Spectroscopy (Academic Press, London-San Diego, 1993).

[22] J. Jimenez, J.W. Tomm. Spectroscopic Analysis of Optoelectronic Semiconductors (Springer, Cham, 2016).

[23] V.A. Volodin, M.D. Efremov, V.Ya. Prints, V.V. Preobrazhenskii, B.R. Semyagin, A.O. Govorov. J. Exp. Theor. Phys. Lett., 66, 47 (1997). doi: $10.1134 / 1.567481$

[24] P.V. Seredin, A.S. Lenshin, V.M. Kashkarov, A.N. Lukin, I.N. Arsentiev, A.D. Bondarev, I.S. Tarasov. Mater. Sci. Semicond. Process., 39, 551 (2015). doi:10.1016/j.mssp.2015.05.067

[25] P.V. Seredin, V.M. Kashkarov, I.N. Arsentyev, A.D. Bondarev, I.S. Tarasov. Phys. B: Condens. Matter, 495, 54 (2016). doi:10.1016/j.physb.2016.04.044

[26] P.V. Seredin, A.S. Lenshin, D.L. Goloshchapov, A.N. Lukin, I.N. Arsentyev, A.D. Bondarev, I.S. Tarasov. Semiconductors, 49, 915 (2015). doi:10.1134/S1063782615070210

[27] Tauc J. Prog. Semicond. Heywood Lond., 9, 87 (1965).

[28] Yu.I. Ukhanov. Optical properties of semiconductors (Nauka, Moscow, 1977).

Редактор Л.В. Шаронова

\section{Spectroscopic study of integrated GaAs/Si heterostructures}

P.V. Seredin ${ }^{1,2}$, D.L. Goloshchapov ${ }^{1}$, I.N. Arsentiev ${ }^{3}$, D.N. Nikolaev ${ }^{3}$, N.A. Pikhtin ${ }^{3}$, S.O. Slipchenko ${ }^{3}$

${ }^{1}$ Voronezh State University, 394018 Voronezh, Russia

2 Ural Federal University, 620002 Yekaterinburg, Russia

3 loffe Institute,

194021 St. Petersburg, Russia 